\title{
AS INTERAÇÕES DAS FORÇAS DE AUTODEFESA DO JAPÃO COM A ORGANIZAÇÃO DAS NAÇÕES UNIDAS E A REPERCUSSÃO PARA A SEGURANÇA NACIONAL DO JAPÃO
}

\author{
Aline Chianca Dantas ${ }^{1}$ \\ Alexandre Cesar Cunha Leite ${ }^{2}$
}

\section{Introdução}

As Forças de Autodefesa do Japão (FAD) vêm, nos anos mais recentes, normalmente coincidentes com os mandatos do Japão como membro não permanente do Conselho de Segurança da ONU (CSONU), atuando em ações conjuntas de peacekeeping demandadas pela Organização das Nações Unidas (ONU). Contudo, a participação das FAD nessas ações conjuntas tem alterado seu caráter determinado pela Constituição japonesa em seu artigo $9^{\circ}$. Este explicita que as FAD devem trabalhar sob o signo da defesa interna e da segurança civil, não devendo constituir-se em um mecanismo de intervenção para além das fronteiras japonesas.

É válido frisar que uma emenda constitucional foi aprovada em setembro de 2015, garantindo a possibilidade de atuação das FAD em operações militares no exterior, embora haja muito questionamento interno e externo a respeito dessa mudança ${ }^{3}$. De todo modo, essa transformação reforçou o papel das FAD e mostra o interesse de fortalecimento da segurança nacional

\footnotetext{
I Estudante de Pós-Graduação em Relações Internacionais na Universidade Estadual da Paraíba(UEPB). E-mail: alinechiancadantas@gmail.com

2 Professor de Relações Internacionais na Universidade Estadual da Paraíba (UEPB). E-mail: alexccleite@gmail.com

3 Disponível em: < http://www.aereo.jor.br/2015/o9/r9/forcas-de-autodefesa-do-japao-agora-podem-realizar-operacoes-militares-no-exterior/ > Acesso em: 22 out. 2015.
} 
japonesa.

Considerado o acima exposto, este trabalho tem o objetivo de analisar a relação entre as Forças de Autodefesa do Japão e a Organização das Nações Unidas, a partir da participação do Japão, por meio das FAD, em operações de paz da ONU. Nesse sentido, são observados os reflexos dessa interação para a segurança nacional japonesa.

Inicialmente, são analisadas as FAD por meio de sua estrutura, características, restrições de sua atuação, relação com a sociedade japonesa e a segurança nacional do país. Ademais, desenvolve-se um debate à luz das teorias liberais e realistas das Relações Internacionais para se discutir as nuances do caráter defensivo das FAD, os aspectos que estão por trás das instituições e do conceito de segurança nacional japonesa.

Em um segundo momento, observa-se a atuação das FAD em operações de paz da ONU, sendo delineados os tipos de participações, os resultados gerais dessas operações, as dificuldades encontradas e as mudanças percebidas nas FAD. Ao mesmo tempo, são utilizadas discussões teóricas realistas e liberais nessa análise.

Posteriormente, é discutida a relação entre as FAD e a ONU, buscando-se perceber se a ONU é um limite para a atuação das FAD internacionalmente, é o objetivo de atuação das FAD, é legitimadora das FAD ou, ainda, se as FAD são as grandes limitadoras de si mesmas. Diante desse debate, são vislumbrados os reflexos da interação entre as duas organizações supracitadas para a segurança nacional japonesa, no sentido de uma possível remilitarização do Japão e de uma preocupação com a imagem do Estado japonês.

Essa discussão também é permeada por análises norteadas pelas perspectivas realista e liberal das relações internacionais, observando-se, por exemplo, o papel da ONU à luz da teoria liberal, com foco na promoção da paz, e da teoria neorrealista que enxerga os interesses estatais inerentes às instituições, podendo-se pensar na ONU como um instrumento de fortalecimento internacional dos atores.

Por fim, diante do debate empreendido no decorrer do texto, podem-se pensar as FAD como limitadoras de si mesmas, em virtude da maneira como a organização incorporou a imposição da sociedade e do próprio Estado japonês do caráter defensivo que ela deve ter (Kurashina 2005); contudo, observando-se essa nova atuação das FAD no meio internacional, através das operações de tipo peacekeeping, a serviço da ONU, é possível pensar em outro momento da segurança nacional japonesa, havendo uma maior preocupação com a imagem do Estado japonês externamente. Nesse sentido, a ONU estaria sendo um instrumento de fortalecimento e legitimação da atu- 
ação das FAD no âmbito interno e internacional. Dessa maneira, a relação das FAD com a ONU pode ser vista como um primeiro passo para a possibilidade de mudança da percepção interna e externa das FAD rumo a objetivos mais abrangentes no futuro. Além disso, as mudanças ainda mais recentes da Constituição Japonesa fortalecem o papel das FAD e mostram o caminho que está sendo seguido pelo Japão em termos de sua segurança nacional.

\section{Contextualizando as Forças de Autodefesa do Japão}

Segundo Kurashina (2005), as Forças de Autodefesa do Japão emergiram entre 1945 e I960 e estavam relacionadas às limitações oriundas do artigo $9^{\circ}$ da Constituição japonesa ${ }^{4}$, à autodefesa, ao caráter policial e à falta de legitimidade. $\mathrm{O}$ autor supracitado declina que a FAD sobrevive como uma organização de "trabalho sujo", visando à manutenção da pureza da população, em meio à memória dos crimes de guerra. Por tal motivo e pela pecha que carregam, as FAD vivem um processo vicioso de busca de legitimação (Kurashina 2005).

Entretanto, quando se considera o caráter pacifista atribuído ao Estado japonês e os impedimentos de uso da força explicitados constitucionalmente, observa-se que as FAD surgiram para responder às necessidades imediatas da situação de segurança doméstica do Japão, tendo em vista a ocupação (e influência) estadunidense do território japonês. Ao fim e ao cabo, segundo a argumentação presente em Kurashina (2005), as FAD acabam por funcionar como uma força policial.

Durante esse processo de formalização das FAD, houve o incentivo estadunidense para sua consolidação visando o combate a invasões diretas ou indiretas ao território japonês. Nesse sentido, em I953, foram criadas leis que efetivamente modelaram as FAD e a Agência de Defesa. Já em I954, ocorreu uma reforma que possibilitou a existência das três esferas das FAD, a saber: terrestre, marítima e aérea. Posteriormente, ainda segundo Kurashina (2005), houve uma reinterpretação do art. $9^{\circ}$ da Constituição, no sentido de possibilitar a existência de um poder de defesa militar para as FAD.

No que concerne à organização e à constituição das FAD, é pertinente destacar os princípios que as permeiam, quais sejam: (i) política orientada

4 Art. $9^{\circ}$ da Constituição Japonesa: “Aspiring sincerely to an international peace based on justice and order, the Japanese people forever renounce war as a sovereign right of the nation and the threat or use of force as means of settling international disputes. In order to accomplish the aim of the preceding paragraph, land, sea, and air forces, as well as other war potential, will never be maintained. The right of belligerency of the state will not be recognized." Disponível em: <http://www.solon.org/ Constitutions/Japan/English/english-Constitution.html> Acesso em: I2 jun. 20II. 
exclusivamente para defesa; (ii) não se tornar um poder militar e (iii) observar os três princípios de não proliferação e controle da segurança civil (Kurashina 2005).

Em virtude dos preceitos acima delineados, que regem as atividades das FAD, e das características da própria segurança nacional japonesa, torna-se nítida a compreensão sobre a impossibilidade de envio de tropas japonesas para operações de paz da ONU até então. Assim, o Japão sempre manteve sua relação com o meio internacional e com a ONU por meio de uma diplomacia de cheque (Segura 2006/2007), que se consubstanciava na doação de valores monetários destinados às operações.

A grande discussão sobre o envio das FAD para participar de operações de paz da ONU gira em torno da característica primordial das FAD que é a autodefesa. No tocante a essa questão, é válido tecer uma discussão teórica em torno do que é a defesa e quais são os seus limites, visando a uma melhor compreensão dos receios internos relativos à possível participação em ações internacionais das tropas japonesas.

Problematizando a discussão, Norman Angell (2002, 268), ao delinear a relação entre defesa e agressão, através do seu olhar liberal, pontua que: "A necessidade da defesa provém da existência de um motivo para o ataque. As rivalidades que todos ignoram. Atenuar o motivo para agressão equivale a fomentar o trabalho da defesa." Logo, embora o referido autor reconheça a necessidade da defesa, especialmente na época em que seu livro foi originalmente escrito, tendo em vista o receio da $\mathrm{I}^{\mathrm{a}}$ Guerra Mundial, ela implica em um motivo para a agressão, considerando a crença, na época universal, das vantagens sociais e econômicas da conquista.

Assim, um ator na arena internacional defende-se porque o outro também o faz e, com isso, corrobora-se para aumentar a possibilidade de agressão mútua. É justamente nisso que se encontra a grande ilusão, como declina o autor supramencionado. Nesse sentido, Angell (2002, 269) explicita que: "O que determina a conduta dos homens não são os fatos, mas a ideia que eles fazem desses fatos". Diante disso, as ideias levam a políticas e estas ao armamentismo, reforçando a esfera da defesa e possibilitando uma futura agressão.

Sob essa perspectiva, observa-se que o limiar entre defesa e agressão é extremamente complexo e que a defesa é pensada em termos de animosidades, causas para o ataque e como uma forma de atenuar o motivo para a agressão. Logo, vislumbrando o caso japonês, constata-se que declarar que o Japão prima pela autodefesa é simplesmente apontar que o país utiliza-se de uma estratégia de atenuação das justificativas para ataque. Nesse sentido, a saída das tropas japonesas para participar de operações de paz torna a relação 
defesa e agressão ainda mais tênue. Ademais, afirma-se que, em si mesmo, o termo autodefesa, incorporado pelas FAD, é falho, tendo em vista que não há como pensar em uma defesa que não leve em consideração o outro, como já discutido à luz da perspectiva presente em Norman Angell.

Apesar da celeuma interna para a atuação das FAD em operações de paz, como se pode perceber, por exemplo, pelas discussões sobre as nuances já explicitadas em torno do termo (auto) defesa, a Guerra do Golfo marcou um ponto de inflexão na segurança nacional japonesa e, consequentemente, nas FAD, tendo em vista que, a não participação efetiva de tropas japonesas no conflito gerou uma percepção internacional negativa a respeito da política externa japonesa e, por conseguinte, de sua diplomacia de cheque. Nesse sentido, o Japão resolve participar mais ativamente da ONU, passando, a partir da década de I990, a atuar em operações de paz da referida organização (Segura 2006/2007).

Quanto a esse ponto, é pertinente ressaltar que a participação japonesa em operações de paz da ONU foi marcada por uma pressão externa, especialmente estadunidense; porém, não se deve deixar de referendar que, simultaneamente, existiam forças internas importantes que primavam por essa atuação japonesa através de operações de paz no meio internacional (George I993).

Assim, visualiza-se um momento de transição na diplomacia japonesa, percebendo-se um novo papel do Japão e de suas FAD, as quais passam a atuar em questões ligadas à segurança regional, a operações de paz e de defesa civil. Todavia, o constitucionalismo interno do Japão exerceu influência direta sobre a política externa do país, perpetuando a rigidez da política de segurança japonesa, mesmo diante de mudanças no sistema internacional. O art. $9^{\circ}$ da Constituição Japonesa está conectado diretamente com a perpetuação democrática e a influência cultural (Katzenstein e Okawara I993).

No entanto, apesar da visão ressaltada por Katzenstein e Okawara (I993) ser bastante forte no Japão, não há como deixar de lado as mudanças dentro da estrutura da segurança nacional japonesa diante da Nova Diretriz do Programa de Defesa Japonês - New National Defense Program Guidelines que visa dinamizar as forças de defesa japonesas, buscando operacionalizá-las em resposta aos desafios de segurança. Assim, os grandes objetivos apontados por Joshy M. Paul (2OII) quanto às FAD são: (i) alcançar dinamicidade; (ii) proteger os direitos soberanos japoneses; (iii) atuar apropriadamente na promoção da estabilidade da Ásia; e, (iv) ter um papel mais ativo no ambiente da segurança global. 
As Diretrizes do Programa de Defesa Nacional Japonês 5 delineiam a importância de uma política proativa baseada na contribuição para a paz, na construção de uma arquitetura de defesa ampla, no reforço da aliança com os EUA e na efetividade da força de defesa, mas sem torná-la uma força militar que imponha medo a outros países. No que se refere às FAD, há a preocupação com sua estrutura, no sentido de priorizar suas capacidades marítimas e aéreas, de fortalecer o sistema de inteligência, de transporte, as capacidades de comando, controle, informação e comunicação, resposta a ataques em ilhas remotas e a ataques de mísseis balísticos, dentre outros aspectos.

Conforme Berkofsky (20II), com a adoção do novo programa de defesa japonês, em dezembro de 2010 , muitas transformações foram deflagradas na segurança e na política de defesa japonesas, dentre elas, o Japão deixa de ser obrigado a limitar o gasto com defesa em I\% do Produto Interno Bruto (PIB), podendo, então, aumentar a capacidade militar e de defesa caso ocorram mudanças no ambiente de segurança que demandem novos posicionamentos e ações. O autor supracitado, todavia, frisa que isso não significa que o Japão vai ultrapassar esse I\% de imediato; mas, que passa a ter a possibilidade de fazê-lo, caso a China e a Coreia do Norte (por exemplo) ameacem a soberania nacional. Ademais, observa-se, diante do novo cenário, uma valorização das FAD, um fortalecimento da Guarda Costeira Japonesa (Japan's Coast Guard), uma preocupação com a implementação de um sistema de defesa de mísseis em conjunto com os EUA e uma modernização dos equipamentos militares japoneses.

Não obstante, como retrata Berkofsky (20II), essa perspectiva militar por parte do Japão não é divulgada visto que, oficialmente, o Japão permanece como um país pacifista dotado de uma Constituição coerente com tal percepção. Frise-se, todavia, que as mudanças em torno do artigo $9^{\circ}$, permitindo a atuação externa das FAD demonstra uma ação mais ativa do Japão no âmbito de segurança, em consonância com as diretrizes do novo programa de defesa nacional.

Apesar das mudanças apontadas na segurança nacional japonesa, cujas implicações são refletidas nas FAD, Berkofsky (20II) deixa claro que a perspectiva defensiva do Japão continua. Assim, por meio de uma análise realista das relações internacionais, pode-se cogitar em uma reflexão de que o Japão guia-se através de uma perspectiva realista de caráter estrutural defensiva (Walt apud Elman 2008), pois não atua de maneira perceptivelmente antecipada e visa à manutenção do status quo regional, embora a estratégia japonesa possa mudar em virtude da presença forte e crescente da China e

5 MOD. Disponível em: <http://www.mod.go.jp/j/approach/agenda/guideline/20I4/ pdf/20I3I2I7_e2.pdf > Acesso em: 20 out. 20I5. 
nuclearizada da Coreia do Norte.

O quadro abaixo reforça o interesse de reforço das FAD aéreas e marítimas em termos logísticos.

\section{Quadro 1: FAD e Novas Diretrizes do Programa de Defesa Nacional}

\begin{tabular}{|c|c|c|c|c|}
\hline \multicolumn{3}{|c|}{ Category } & Present (as of the end of FY2013) & Future \\
\hline \multirow{5}{*}{$\begin{array}{l}\text { Ground } \\
\text { Self-Defense } \\
\text { Force }\end{array}$} & \multicolumn{2}{|c|}{$\begin{array}{l}\text { Authorized Number of Personnel } \\
\text { Active-Duty Personnel } \\
\text { Reserve-Ready Personnel }\end{array}$} & $\begin{array}{r}\text { approx. } 159,000 \\
\text { approx. } 151,000 \\
\text { approx. } 8,000\end{array}$ & $\begin{array}{r}159,000 \\
151,000 \\
8,000\end{array}$ \\
\hline & \multirow[t]{4}{*}{$\begin{array}{l}\text { Major } \\
\text { Units }\end{array}$} & Rapid Deployment Units & $\begin{array}{r}\text { Central Readiness Force } \\
1 \text { armored division }\end{array}$ & $\begin{array}{r}3 \text { rapid deployment divisions } \\
4 \text { rapid deployment brigades } \\
1 \text { armored division } \\
1 \text { airborne brigade } \\
1 \text { amphibious rapid deployment brigade } \\
1 \text { helicopter brigade }\end{array}$ \\
\hline & & Regional deployment Units & $\begin{array}{l}8 \text { divisions } \\
6 \text { brigades }\end{array}$ & $\begin{array}{l}5 \text { divisions } \\
2 \text { brigades }\end{array}$ \\
\hline & & Surface-to-Ship Guided Missile Units & 5 surface-to-ship guided missile regiments & 5 surface-to-ship guided missile regiments \\
\hline & & Surface-to-Air Guided Missile Units & 8 anti-aircraft axtillery groups/regiments & 7 anti-aircraft artillery groups/regiments \\
\hline \multirow{2}{*}{$\begin{array}{l}\text { Maritime } \\
\text { Self-Defense } \\
\text { Force }\end{array}$} & $\begin{array}{l}\text { Major } \\
\text { Units }\end{array}$ & $\begin{array}{l}\text { Destroyer Units } \\
\text { Submarine Units } \\
\text { Minesweeper Units } \\
\text { Patrol aircraft Units }\end{array}$ & $\begin{array}{r}4 \text { flotillas } \\
\text { (8 divisions) } \\
5 \text { divisions } \\
5 \text { divisions } \\
1 \text { flotilla } \\
9 \text { squadrons }\end{array}$ & $\begin{array}{r}4 \text { flotillas } \\
\text { (8 divisions) } \\
6 \text { divisions } \\
6 \text { divisions } \\
1 \text { flotilla } \\
9 \text { squadrons }\end{array}$ \\
\hline & $\begin{array}{c}\text { Major } \\
\text { Equipment }\end{array}$ & $\begin{array}{l}\text { Destroyers } \\
\text { (Aegis-Equipped Destroyers) } \\
\text { Submarines } \\
\text { Combat Aircraft }\end{array}$ & $\begin{array}{r}47 \\
(6) \\
\\
16 \\
\text { approx. } 170\end{array}$ & $\begin{array}{r}54 \\
(8) \\
22 \\
\text { approx. } 170 \\
\end{array}$ \\
\hline \multirow[t]{2}{*}{$\begin{array}{l}\text { Air } \\
\text { Self-Defense } \\
\text { Force }\end{array}$} & $\begin{array}{l}\text { Major } \\
\text { Units }\end{array}$ & $\begin{array}{l}\text { Air Warning \& Control Units } \\
\text { Fighter Aircraft Units } \\
\text { Air Reconnaissance Units } \\
\text { Aerial Refueling/Transport Units } \\
\text { Air Transport Units } \\
\text { Surface-to-Air Guided Missile Units }\end{array}$ & $\begin{array}{r}8 \text { warning groups } \\
20 \text { warning squadrons } \\
1 \text { AEW group (2 squadrons) } \\
12 \text { squadrons } \\
1 \text { squadron } \\
1 \text { squadron } \\
3 \text { squadrons } \\
6 \text { groups }\end{array}$ & $\begin{array}{r}28 \text { warning squadrons } \\
1 \text { AEW group (3 squadrons) } \\
13 \text { squadrons } \\
2 \text { squadrons } \\
3 \text { squadrons } \\
6 \text { groups }\end{array}$ \\
\hline & $\begin{array}{c}\text { Major } \\
\text { Equipment }\end{array}$ & $\begin{array}{l}\text { Combat Aircraft } \\
\text { Fighters }\end{array}$ & $\begin{array}{l}\text { approx. } 340 \\
\text { approx. } 260\end{array}$ & $\begin{array}{l}\text { approx. } 360 \\
\text { approx. } 280\end{array}$ \\
\hline
\end{tabular}

Fonte: Japan Ministry of Defense. National Defense Program Guidelines for FY 2014 and beyond 2013,31 .

Diante de todo o quadro delineado acima, percebe-se, nas entrelinhas 
da segurança nacional japonesa e das FAD, um esforço direcionado para o desenrolar das discussões que serão tecidas nos próximos pontos e, especialmente, na discussão final sobre a relação entre as FAD e a ONU e os reflexos para a segurança nacional japonesa. Assim, o tópico seguinte visa a compreender como se dá a atuação das FAD em operações de paz da ONU.

\section{A relação entre as Forças de Autodefesa do Japão e as Oper- ações de Paz}

A partir da aprovação da lei de operações de manutenção de paz (Peacekeeping Operations Law) em I992, foi permitido ao Japão enviar tropas das FAD para o meio internacional. Sua primeira ação teve como objetivo participar das missões de paz no Camboja. Assim, a United Nations Transitional Authority in Cambodia - UNTAD-, operação de tipo peacekeeping, teve a participação de 1300 japoneses, dentre eles estavam engenheiros encarregados de monitorar o cessar fogo, policiais e observadores de eleições (Guimarães 2005).

É pertinente ressaltar que a justificativa para a atuação das FAD em operações de manutenção de paz encontra-se no argumento de que essa ação consiste em uma autodefesa coletiva (Berkofsky 20II); contudo, se o termo autodefesa já possui problemas, como analisado anteriormente, o vocábulo autodefesa coletiva é algo ainda mais difícil de ser sustentado ${ }^{6}$.

Apesar da lei sobre operações de tipo peacekeeping ter garantido a participação das FAD em operações de paz, o art. $9^{\circ}$ da Constituição japonesa continuava inalterado, gerando intensos e acalorados debates sobre a inconstitucionalidade dessa lei e a violação do art. $9^{\circ}$ (George I993). Segundo Uehara (2003), alguns analistas acreditam que as FAD poderiam participar das ações conjuntas sem armas, outros, conforme Wilborn (I994), visualizam as FAD como possíveis instrumentos para agressão no futuro, em consonância com o debate entre defesa e agressão já empreendido anteriormente. Os alarmistas, como ilustra George (I993), diziam que a participação japonesa em operações de paz poderia ser um desejo de mascarar uma intenção de possuir um papel militar internacional ou ainda de reviver o militarismo japonês7.

Todavia, embora haja toda essa discussão interna e internacional sobre a participação das FAD em operações de paz, o fato é que elas vêm atuando no âmbito internacional, devendo, no entanto, seguir algumas regras,

6 Não é o objetivo desse texto entrar na discussão conceitual no que tange ao termo autodefesa. 7 É válido relembrar a mudança ocorrida no ano de 2015 no sentido de possibilitar a atuação externa dessas forças. 
quais sejam: (i) deve ter sido alcançado acordo de cessar fogo entre as partes em conflitos armados antes do ingresso das FAD; (ii) é necessário o consentimento pelos países hospedeiros, bem como das partes em conflito armado, para realização de operações de paz da ONU; (iii) as operações devem manter a imparcialidade sem favorecer nenhuma das partes do conflito armado e (iv) o uso de armas deve ser limitado ao mínimo necessário à proteção das vidas das pessoas. Assim, todos os requisitos apontados devem ser seguidos, pois, caso contrário, o governo japonês pode retirar as FAD do local em que se encontram findando a ação e sua participação na operação (Kurashina 2005).

Através de suas possibilidades, as FAD depois da atuação no Camboja, participaram de operações em Moçambique em 1993, por meio de uma missão da ONU denominada United Nations Operation in Mozambique - UNUMOZ - para a qual foram enviados I6o especialistas. Em Ruanda, I994, o Japão mandou 400 especialistas para, especialmente, apoiar os refugiados. Desde I996, aproximadamente 800 japoneses foram enviados para as Colinas do Golã. Já em I999, 2300 indivíduos foram mandados para o Timor Leste para participar da United Nations Transitional Administration in East Timor - UNTAET. Em 200I, foram enviados navios para atuação no Oceano Índico, buscando combater o terrorismo dentro de uma estratégia proposta pelos EUA (Guimarães 2005).

Por sua vez, em 2003-2004, o Japão atuou no Iraque e as FAD passaram, em 2004, a incluir apoio ao processo de reconstrução do país (Kawahara apud Guimarães 2005). Segundo Fouse (2007), essa foi a primeira vez, após a $2^{\mathrm{a}}$ Guerra Mundial, que os soldados puderam carregar armas com eles e, conforme Pilling (2004), foi a primeira atuação das FAD sem que tenha havido um mandato da ONU para tal. Diante dessa última informação, percebe-se que a ONU não é, então, uma limitação para a atuação das FAD, mas sim um reforço e uma maneira de promover o seu fortalecimento.

Dessa maneira, observa-se que todas as atuações das FAD citadas acima estão relacionadas com operações de tipo peacekeeping, ou seja, são intervenções que utilizam a presença militar como veículo de operacionalização (Kurashina 2005), embora existam outras formas de atuação que mantêm esse caráter não militar, como operações de ajuda a desastres, de ajuda humanitária e operações antipirataria (White Paper 2009 e 2012). Ademais, pode-se perceber que todas as participações das FAD citadas estavam ligadas a um mandato da ONU (reflexo da necessidade de atuação do Japão enquanto membro não permanente do Conselho de Segurança da ONU), exceto a operação no Iraque, como já foi descrito acima.

Diante dessas observações, seria relevante pensar sobre as implicações dessas operações na segurança nacional japonesa. Nesse sentido, a 
atuação das FAD no meio internacional pode estar funcionando como um instrumento de soft power, promovendo a imagem do Estado japonês de maneira suave; mas, ao mesmo tempo, como uma forma de treinamento e aprimoramento dessas forças, que, no âmbito interno, seriam mais vigiadas e impedidas de fazer uso de determinados equipamentos, podendo levar a uma abertura para a remilitarização do Japão. Kurashina (2005), por outro lado, não corrobora com essa possibilidade de remilitarização do Japão por meio da atuação das FAD externamente, pois mediante entrevistas realizadas com membros das FAD japonesas, percebe que há uma limitação das FAD no sentido de se voltarem para autodefesa, que foi incorporada pelos membros da organização ao longo do tempo, impedindo essa caracterização de cunho mais militar/belicoso.

Portanto, como declinam alguns autores (Kurashin, 2005; Fouse 2007), observa-se uma experiência positiva das atuações japonesas em operações de paz solicitadas pela ONU. Essas estariam refletindo na aproximação da figura do "soldado japonês", na modificação da percepção da FAD enquanto organização e da maior aceitação de seus membros dentro do seio social. No que diz respeito à nova percepção das FAD, outros fatores devem ser considerados além das operações de paz, tais como, mídia, tentativas de quebra de autoridade para aproximação social e inclusões de gênero, dentre outras (Kurashina 2005). Todavia, a contribuição das operações de paz parece ter sido fundamental para a nova roupagem das FAD e sua visualização mais positiva pela população interna e internacional.

Vale acrescentar as dificuldades encontradas pelas FAD em sua atuação nas operações de paz, trazendo indagações em torno de suas características basilares. Internamente, há o questionamento do papel das FAD nessas operações, tendo em vista os obstáculos existentes para sua ação, declarando que elas seriam altamente custosas para desempenharem o papel que civis poderiam fazê-lo. Além disso, existem as diferenças que os próprios membros das FAD sentem frente às tropas de outros países, pois muitas são bem mais organizadas tecnicamente (Kurashina 2005).

Contudo, essas participações de operações de paz permitem, por outro viés, ampliar o ego dos membros das $\mathrm{FAD}$, que se sentem mais úteis para sua própria sociedade, e isso fortalece a interação entre esses dois grupos separados historicamente (Kurashina 2005) e pode dar margem para uma atuação mais ativa do Japão no âmbito internacional, por meio de instrumentos ditos pacíficos.

Fazendo analogia com a abordagem de Aragusuku (20II) sobre a ajuda externa japonesa (ODA), a atuação japonesa através das operações de paz poderia ser caracterizada como uma estratégia de dominação simbólica, por 
meio da qual o discurso altruísta de autodefesa coletiva proporcionaria, de maneira suave, uma ampliação da força do Japão no âmbito externo associada a uma boa imagem do Estado.

Sustenta tal argumentação, a percepção de Aurelia George (I993), pois a autora acredita que fazer contribuições para a comunidade internacional não é a prioridade do governo japonês, mas sim o aprimoramento e a mobilidade das FAD no nível internacional, alterando-se a percepção a respeito da posição japonesa no jogo internacional. Considerando o exposto, passa-se, no tópico seguinte, para a análise da relação existente entre as FAD e a ONU e dos reflexos em termos de segurança nacional.

\section{As Forças de Autodefesa do Japão, sua relação com a ONU e os reflexos para a segurança nacional japonesa}

Após toda a abordagem delineada acima, é interessante discutir o papel da ONU frente aos interesses estatais, tendo em vista a atuação das Forças de Autodefesa do Japão e a segurança nacional do Japão.

Assim, para Kant (2008), a liga dos povos, compreendida analogamente ao que hoje é a ONU, deveria ser uma comunidade moral cujo valor superasse o das comunidades nacionais, na busca do bem comum; e o Estado, por sua vez, embora tendesse a se utilizar da sabedoria, seria conduzido pela prudência que se encarregaria de coadunar suas ações em consonância com os valores morais, logo, diante de tais pressupostos, seria possível a paz perpétua.

No entanto, o caso aqui em análise ilustra que nem sempre o interesse dos Estados é altruísta, ao contrário, os países agem, na maioria das vezes, egoisticamente, mas a prudência acompanha a racionalidade estatal. Observando o caso japonês, constata-se que a atuação das FAD em operações de paz da ONU não visa apenas ao bem comum, pois a competição inerente à anarquia internacional, conforme as premissas realistas, impele os Estados a pensarem em termos de poder e sobrevivência. Dessa forma, um interesse que, por exemplo, estaria por trás da atuação japonesa seria a busca por um assento permanente no Conselho de Segurança da ONU, como observa Pilling (2004).

Assim sendo, as operações de paz da ONU podem ser pensadas como um elemento do liberalismo republicano (Baldwin I993), tendo em vista a valorização da paz e da democracia para o alcance do bem comum; mas também por uma ótica neorrealista, ressaltando a atuação dos Estados enquanto controladores das organizações internacionais, conforme bem res- 
salta Mearsheimer (I995).

Assim, quando Mitrany (I948) desenvolve sua tese dentro da abordagem funcionalista de que as organizações internacionais podem atuar como responsáveis apenas pelo papel técnico, promovendo a cooperação, é perceptível um distanciamento da realidade, pois na prática os Estados são os grandes constituidores das organizações internacionais e, como fica perceptível no caso da ONU, sua ação está vinculada aos Estados, tanto por meio da Assembleia Geral quanto do Conselho de Segurança. Logo, simples ações da ONU voltadas para operações de paz levam em consideração um Estado hospedeiro e tropas disponibilizadas pelos Estados para atuarem no local, como é o caso do Japão. Por conseguinte, o processo de spill over, por meio do qual Haas (i956) acredita que uma cooperação em uma área leva a outra em um aspecto diferente só é verdade quando os Estados possuem interesse de estabelecer outros tipos de cooperações, pois como ele mesmo aponta em seus escritos, o elemento político também importa para as instituições.

Nesse aspecto, como ilustram Keohane e Nye (2000), por meio de suas discussões sobre a interdependência complexa, as organizações internacionais são instrumentos de negociação e cooperação; contudo, poder e interesse não podem ser deixados de lado. Todavia, eles afirmam que as instituições são capazes de resolver problemas dos quais os Estados estejam interessados em solucionar, pois o que se vive é uma interdependência assimétrica. No entanto, Mearsheimer (I995) é ainda mais incisivo quando fala que os ganhos relativos são inerentes às escolhas dos Estados; então, pensar numa atuação voltada para as operações de paz, seria ter em mente uma cooperação japonesa articulada para obter ganhos para si levando em consideração os ganhos dos demais países ao fazer o mesmo.

Atentando para a discussão teórica estabelecida acima, passa-se a analisar de maneira prática a relação da ONU com as FAD e os reflexos para a segurança nacional japonesa. A primeira pergunta que pode ser lançada ao discutir essa relação é se a ONU é um limite para a atuação das FAD no meio internacional, tornando a atuação dessa última organização vinculada bilateralmente à ONU e mantendo a segurança nacional japonesa com caráter defensivo. Por meio das abordagens desenvolvidas ao longo do trabalho, percebe-se que não é isso que vem ocorrendo de fato, até mesmo porque as FAD tiveram atuação desvinculada da ONU no caso do Iraque, estando essa participação muito mais relacionada com a aliança existente com os Estados Unidos. Ademais, como aponta Kurashina (2005), a ONU não possui uma definição sucinta de operação de paz, o que daria margem para uso de qualquer atividade militar para resolver conflitos armados.

Dessa maneira, o centralismo da segurança nacional japonesa em tor- 
no da ONU pode ser pensado muito mais como uma estratégia do governo japonês para manter o caráter pacífico do país do que como o resultado da falta de opções de atuação do Japão no meio internacional.

Como um segundo questionamento nesse tópico tem-se: seria a ONU um objetivo das FAD? Essa resposta será uma complementação da anterior, pois se vê que a ONU vem sendo sim um foco da segurança nacional japonesa, em virtude da conexão das políticas pacíficas da ONU e do Estado japonês. Quando se aprofunda a percepção sobre as FAD, observa-se que os seus membros veem a ONU como um dos seus objetivos de atuação, por se sentirem mais úteis e poderem efetivamente atuar em nome do país.

A terceira pergunta que pode ser tecida é se as FAD seriam limitadoras de si mesmas. Aqui se percebe que, como analisa Kurashina (2005), o antimilitarismo existente dentro do Japão, em virtude das consequências das guerras, embutiu na organização a incorporação de sua atuação voltada para autodefesa e isso provoca sim uma autolimitação das FAD. Contudo, como essa limitação é decorrente das amarras estruturais do Estado japonês e não da própria organização, pode ser que, posteriormente, através das atuações em operações internacionais, possa haver uma mudança da mentalidade dos membros das FAD no sentido de buscarem um papel mais ativo no meio internacional, afastando-se um pouco do caráter estrito da autodefesa. Inclusive, pode ser que a própria estratégia de segurança japonesa mude e isso levaria a uma transformação das próprias FAD.

Ainda pode ser depreendida a seguinte discussão: seria a ONU legitimadora das FAD? Esse é o ponto nevrálgico desse trabalho, pois leva em consideração que a atuação das FAD em operações de paz da ONU estaria reforçando tanto a primeira organização quanto a própria figura do Estado japonês no âmbito internacional. Parece que é justamente isso que vem ocorrendo, pois a participação das FAD em operações de paz da ONU vem possibilitando o estreitamento da relação da instituição com o povo japonês em geral, quebrando um pouco a separação social existente entre as duas esferas (Kurashina 2005), o que reforça a atuação dessas forças e pode dar abertura para uma possível mudança na segurança nacional japonesa de maneira implícita e não tão perceptível.

Acrescenta-se ainda que a participação em operações de peacekeeping é um bom treino para ato de defesa, possibilitando um aprendizado de técnicas relevantes que podem facilitar a estratégia em caso de invasão ao território nacional e reconhecimento do inimigo (Kawano apud Kurashina 2005).

Dessa forma, a contribuição para a paz mundial dada pelas FAD, está por trás de uma lógica de promoção da imagem do Japão, fortalecimento da segurança do país, preocupação regional de integração, elevação do perfil 
político do país no cenário internacional, ampliação do respeito pelo Japão, dentre outros pontos (George I993).

Nesse sentido, a dupla percepção que se pode ter da ONU, de um lado, como instituição promotora da paz internacional e, de outro, como instrumento de atuação dos Estados na busca de seus interesses próprios, contrapõe-se ao pensamento utópico de Kant (2008) de que seria possível existir uma instituição moral que buscasse o bem comum e estivesse desvinculada do interesse dos Estados.

Portanto, esse trabalho incita maiores discussões a respeito do ressurgimento militar japonês à luz do fortalecimento das FAD. Essa discussão é corroborada pelos autores que acreditam na normalização do Estado japonês, como Pyle (2007), apontando para as reformas pelas quais o Japão vem passando desde a década de 1990 e as implicações do ambiente internacional sobre o que se denomina de segurança nacional japonesa, levando à sua abertura em termos militares, especialmente quando se considera as nuances do espectro regional asiático.

\section{Considerações finais}

Considerando tudo que foi exposto até então, observa-se que as FAD vêm tendo um papel cada vez mais ampliado e, ainda que haja restrições para a atuação dessas forças, essas barreiras aos poucos estão sendo quebradas, possibilitando inclusive discussões sobre o real caráter defensivo das FAD e da segurança nacional japonesa.

Ao se analisar a relação entre as FAD e a ONU, fica mais nítido o crescimento das FAD, tendo em vista que essas forças não estão atreladas à atuação dentro da relação bilateral com a ONU, já que a participação japonesa nas operações de paz no Iraque não estava vinculada a um mandato da ONU. Sendo assim, a ONU seria um objetivo das FAD como uma forma de manter o discurso de centralidade que as Nações Unidas ocupam dentro da política nacional japonesa. Por outro lado, vê-se que a ONU seria muito mais uma ferramenta de legitimação da atuação das FAD no meio internacional.

Quanto à autolimitação das FAD, essa realmente existe, todavia, é decorrente de um processo de internalização do caráter defensivo e das demais restrições impostas a essas forças e não advém da própria organização; sendo assim, com a mudança da percepção da população japonesa dessas forças e o afrouxamento das fronteiras japonesas para a atuação das FAD, possibilitado pela política do país, está ocorrendo uma abertura clara para a ascensão dessas forças interna e externamente, permitindo que elas atuem 
não apenas visando à defesa do Japão, mas sim, pensando na segurança internacional (George i993).

É relevante expressar que o crescimento das FAD representa não apenas uma mudança na organização e na segurança nacional japonesa, mas implicações para a própria relação bilateral do Japão com os EUA, tendo em vista que esse novo fato pode significar uma maior autonomia japonesa frente à nação estadunidense.

Nesse sentido, é possível que a atuação das FAD tenha sido o instrumento encontrado pelo Japão para promover a normalização do país de maneira suave, mantendo explicitamente o caráter pacifista e a boa imagem externa do país e, implicitamente, possibilitando que uma organização japonesa importante para a área de segurança cresça e se desenvolva. Assim, pode-se pensar na adoção por parte do Japão da filosofia do pacifismo ativo, por meio da qual o poder militar seria um instrumento necessário para se alcançar a paz.

Portanto, parece que está havendo sim uma abertura da segurança nacional japonesa, através da atuação das FAD em operações de paz no meio internacional, embora esse processo ainda seja tímido. Com a continuação dessas operações, a tendência é que no futuro seja mais perceptível uma atuação mais ativa do Japão no meio internacional.

\section{REFERÊNCIAS}

Angell, Norman. 2002. A Grande Ilusão. Brasília: Editora Universidade de Brasília, 26I-289.

Aragusuku, Juliano Akira de Souza. 20II "A assistência oficial para o desenvolvimento na política externa japonesa.”. Disponível em: <http:// www.santiagodantassp.locaweb.com.br/br/arquivos/defesas/aragusuku_dissertacao_mestrado.pdf> Acesso em: 02 jun. 2012.

Baldwin, David A. 1993. "Neoliberalism, Neorealism and World Politics". In: Neorealism and Neoliberalism: The Contemporary Debate. New York: Columbia University Press.

Berkofsky, Axel. 20II Japanese Security and Defense Policies: Trends, Threat Perceptions and Prospects. In: Asian Paper.

Constituição Do Japão. 2012 Acesso em: I2 fev. 2012 <http://www.solon.org/ Constitutions/Japan/English/english-Constitution.html>

Elman, Colin. Realism. 2008 In: Security Studies: An Introduction. Ed. Paul 
D. Williams. London and New York: Routledge, I5-28.

Fouse, David. 2007. Japan's Dispatch of the Ground Self Defense Force to Iraq: Lessons Learned. Disponível em: <http://www.apcss.org/Publications/Japan's\%2oDispatch\%2oof\%2othe\%20GSDF\%2oto\%2oIraq. Fouse.doc.pdf > Acesso em: I5 jan. 2012.

George, Aurelia. I993. “Japan's Participation in U.N. Peacekeeping Operations: Radical Departure or Predictable Response?" Asian Survey 33(6,): 560-575.

Guimarães, Lytton L. 2005 A inserção político diplomática do Japão no cenário internacional. Disponível em: <http://vsites.unb.br/ceam/neasia/boletins/artigo_lytton20406.pdf> Acesso em: o8 jun. 2012.

Haas, Ernst. 1956. Regionalism, Funtionalism and the Universal International Organization. World Politics, 8(2).

JAPAN MINISTRY OF DEFENSE -MOD. 20I3. National Defense Program Guidelines. Disponível em: <http://www.mod.go.jp/j/approach/agenda/guideline/20I4/pdf/20I3I2I7_e2.pdf > Acesso em: 20 out. 20I5.

Kant, Immanuel. 2008. A paz perpétua. Porto Alegre: L\&PM.

Katzenstein, Peter J., e OKAWARA, Nobuo. I993. “Japan's National Security: Structures, Norms and Policies". International Security. I7(4): 84-II8.

Keohane, Robert e NYE, Joseph. 2000. "Realism and Complex Interdependence.” In: LINKLATER, Andrew (Ed.). International Relations. Vol. II. Florence: Routledge, 7I8-73I.

Kurashina, Yuko. 2005. Peacekeeping participation and identity changes in the Japan Self Defense Forces: Military Service as "Dirty Work". Disponível em: <http://drum.lib.umd.edu/bitstream/ı903/2967/r/umiumd-2760.pdf> Acesso em: or jun. 2012.

Mearsheimer, John J. I994/I995. "The false promise of International Institutions." International Security.I9(3): 5-49.

Mitrany, David. I948. The functional approach in International Organization. In: International Affairs.

Paul, Joshy M. 20II. China and Japan: Scrambling for Regional Space. Disponível em: <http://www.nids.go.jp/english/publication/commentary/ pdf/commentaryo23.pdf> Acesso em: 25 jan. 2012.

Pilling, David. 2004. The role of Tokyo's Self Defense Forces is increasingly beset by contradictions. In: Financial Times.

PODER AÉREO. 20I5. Disponível em: < http://www.aereo.jor.br/20I5/o9/19/ forcas-de-autodefesa-do-japao-agora-podem-realizar-operacoes-militares-no-exterior/ > Acesso em: 22 out. 20I5. 
Pyle, Kenneth B. 2007. Japan Rising: The Resurgence of Japanese Power and Purpose. New York: Public Affairs.

Segura, Caterina Garcia. 2006/2007. Seguridad humana: conceptos, experiencias e propuestas. In: Revista CIDOB D’AFERS INTERNACIONALS, 76: 79-95.

Uehara, Alexandre Ratsuo. 2003. A política externa do Japão no século XX: o que faltou? São Paulo: Annablume: Fundação Japão.

WHITE PAPER, 2009. Disponível em: <http://www.mod.go.jp/e/publ/w_ paper/2009.html> Acesso em: I3 mar.2013.

WHITE PAPER, 20I2. Disponível em: <http://www.mod.go.jp/e/publ/w_paper/20I2.html> Acesso em: I3 mar.2013.

Wilborn, Thomas L. I994. Japan's Self Defense Forces: What Dangers to Northeast Asia?. Disponível em: <http://www.strategicstudiesinstitute. army.mil/pdffiles/pubio2.pdf> Acesso em: I5 jan. 20 I2.

\section{RESUMO}

Este trabalho analisa as relações entre as Forças de Autodefesa do Japão e a Organização das Nações Unidas, através da participação da primeira instituição em operações de paz comandadas pela segunda. Posteriormente, são observados os reflexos dessa interação para a segurança nacional japonesa, no sentido de uma possível remilitarização do país e da manutenção da boa imagem do Estado japonês no cenário internacional.

\section{PALAVRAS-CHAVE}

Forças de Autodefesa do Japão; ONU; Segurança nacional japonesa.

Recebido em 18 de Maio de 2015. Aprovado em 25 de Novembro de 2016. 